\title{
PISOS INTERTRAVADOS COM A INCORPORAÇÃO DE RESÍDUOS MINERAIS
}

\section{Concrete Paving Blocks with the incorporation of mineral waste}

\author{
Rayane Campos Lopes ${ }^{1}$, Edgar Bacarji ${ }^{2}$
}

Recebido em 16 de fevereiro de 2014; recebido para revisão em 03 de junho de 2014; aceito em 18 de julho de 2014; disponível on-line em 29 de agosto de 2014.

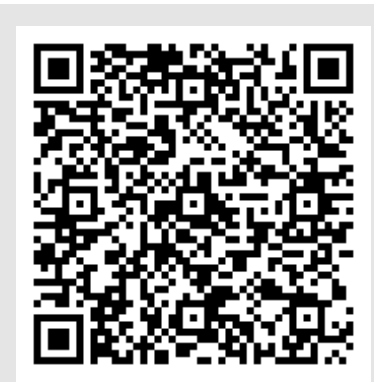

\section{PALAVRAS CHAVE:}

Resíduo da construção;

Pó de brita;

Pisos intertravados.

\section{KEYWORDS:}

Buidings Waste;

Quarry dust;

concrete paving blocks.

\section{* Contato com o autor:}

${ }^{1}$ e-mail : rayaneclopes@hotmail.com (R.C. Lopes)

Aluna de iniciação científica da Escola de Engenharia Civil - Universidade Federal do Goiás - EEC/UFG.

2e-mail : edgarbacarji@hotmail.com (E. Bacariji)

Professor Associado da Escola de Engenharia Civil da Universidade Federal do Goiás - EEC/UFG.

\begin{abstract}
RESUMO: Na britagem de rochas destinadas à produção de agregados para a construção civil, gera-se uma grande quantidade de resíduo (areia artificial e pó de brita). A areia artificial já é utilizada como agregado miúdo em substituição à areia natural, de rio. 0 pó de brita, ao contrário, permanece estocado nos pátios das empresas produtoras de agregados e a sua disposição inadequada pode causar problemas ambientais e à saúde humana. Buscando uma destinação técnica e ambientalmente correta para esse resíduo, estudou-se nessa pesquisa o efeito da sua incorporação nas propriedades mecânicas e de durabilidade de pisos intertravados. Foram analisadas as resistências à compressão aos 07, 28 e 90 dias e as absorções aos 28 dias. Foram estudados seis traços: um traço de referência (sem adição de resíduo) e outros cinco traços com substituição de $10 \%$ dos agregados totais pelo resíduo. Avaliou-se também o efeito a adição de um aditivo plastificante nos traços referidos. Os resultados demonstraram que a incorporação do resíduo foi benéfica. Houve aumento de resistência verificado no traço 1:2 (cimento:agregados totais secos) com resíduo em relação ao traço 1:2 sem resíduo. Quanto a absorção, não houve uma diferença significativa entre estes traços. Quanto ao aditivo plastificante, o seu efeito provocou significativos decréscimos de valores tanto nas resistências quanto nas absorções, em relação aos traços sem aditivos. Pela perspectiva da preservação ambiental os resultados também foram promissores haja vista que em todos os traços substituíram-se $10 \%$ dos agregados totais (areia e brita) pelo resíduo gerado na britagem das rochas.
\end{abstract}

ABSTRACT: In crushing rocks for the production of aggregates for the construction industry, a large amount of residue (artificial sand and quarry dust) is generated. The artificial sand is already used as fine aggregate replacing the natural sand of the river. The quarry dust, instead, remains stored in the courtyards of the producers of aggregates and their improper disposal can cause environmental problems and to human health. Seeking a technically and environmentally correct disposal for this waste, in this research it is studied the effect of incorporation on the mechanical properties and durability of concrete paving blocks. It was analyzed the compressive strength at 07,28 and 90 days and the absorptions at 28 days. Six mixtures were studied: one reference mixture 1:2 (cement: total dry aggregates) (without addition of quarry dust) and five with replacement of $10 \%$ of the total aggregate for the quarry dust. It was also evaluated the effect of the addition of a plasticizer additive in the features mentioned above. The results showed that the incorporation of quarry dust was beneficial. There was an increase of resistance found in mixture 1:2 with quarry dust compared to mixture 1:2 without quarry dust. As the absorption, there was no significant difference between these mixtures. As the plasticizer additive, its effect caused significant decreases in both resistance values and the absorptions as compared to mixtures not containing additives. From the perspective of environmental protection, results were also promising considering that in all mixtures was replaced $10 \%$ of the total aggregate (sand and coarse aggregate) for quarry dust generated by the crushing of rocks. 


\section{INTRODUÇÃO}

A indústria da construção civil é uma grande consumidora de recursos naturais, estimase algo entre 20 e $50 \%$ do total de recursos naturais consumidos pela sociedade (Sjöström, 1996 apud Dal Molin et al. 2005) e, consequentemente, uma grande geradora de resíduos. O concreto é o material construtivo mais utilizado pelo homem, sendo parte desse material composto por agregados. Na fabricação desses agregados, resíduos são gerados. E cada vez mais há a necessidade de uma destinação adequada desses resíduos, sendo uma boa alternativa sua inserção na fabricação de novos produtos.

No atual padrão de consumo dos recursos naturais, novas alternativas e a busca por um desenvolvimento sustentável passa de um luxo ou uma propaganda para uma necessidade, principalmente na engenharia civil.

Dentro do desenvolvimento sustentável, os pisos intertravados de concreto se tornaram uma boa alternativa na pavimentação de vias, estacionamentos e calçadas. Com a reconstrução dos países arrasados pela Segunda Guerra Mundial, houve a necessidade de uma pavimentação rápida, com a fabricação industrial de peças pré-moldadas de concreto (PPC) (Abi-Ackel, 2009). Assim, substituíram-se outros tipos de revestimentos que foram usados anteriormente como blocos de tijolos de argila, pedras talhadas e blocos de madeira. Em meados da década de 1960, as PPC já estavam consolidadas comercialmente na América Central, América do Sul e África do Sul. (Purificação, 2009).

No começo da sua aplicação no Brasil, por não obedecerem aos critérios mínimos necessários ao bom desempenho desse tipo de pavimento, a imagem dos blocos de concreto para pavimentação foi prejudicada. Enquanto isso, em outros países, sua utilização crescia, com um grande avanço tecnológico por meio do desenvolvimento de técnicas de dimensionamento, construção, novos formatos, aumento da resistência e durabilidade e avanços na normalização. Dentre as vantagens e facilidade da utilização desse tipo de pavimento estão: versatilidade do material, facilidade de estocagem e homogeneidade, a imediata utilização do pavimento, mão de obra não especializada e baixo custo de manutenção HALLACK (2000).

Dentro desta mesma perspectiva de sustentabilidade, diversas pesquisas vêm sendo realizadas com o objetivo de avaliar o desempenho dos pisos intertravados de concreto quando há incorporação de diferentes resíduos, substituindo parte dos agregados ou parte do cimento.

Com esse objetivo, Purificação (2009) estudou a substituição de parte do cimento por resíduo de polimento de porcelanato juntamente com o uso de agregados reciclados de concreto. Os valores obtidos no ensaio de compressão demonstraram que os pisos estudados apresentaram desempenho mecânico satisfatório, produzindo pisos com vantagens competitivas.

Gencel e Ozel (2011) estudaram os efeitos da substituição de parte dos agregados pelo resíduo do processamento de mármore, com a utilização de dois tipos diferentes de cimento, nas propriedades de pisos intertravados. Apesar de a resistência mecânica diminuir com o aumento do teor de resíduo, houve um aumento da durabilidade e resistência ao desgaste abrasivo, concluindo que tal resíduo pode ser usado como substituição parcial dos agregados convencionais.

Tavares e Franco (2012) estudaram a incorporação de resíduos de galvanoplastia, pela substituição parcial do cimento por dois resíduos (poeira de jateamento e lodo de galvanoplastia). Os pisos produzidos atenderam ao valor estipulado na norma brasileira de resistência à compressão para trafego de veículos leves, apesar de a resistência ter diminuído com o aumento da porcentagem substituída. Esses resíduos, tomados os devidos cuidados, demonstraram serem aceitáveis como matéria prima na construção civil.

\section{OBJETIVOS}

O objetivo desta pesquisa é avaliar o efeito da incorporação do resíduo mineral pó de brita, subproduto da britagem de rochas graníticas, nas propriedades de desempenho mecânico e de durabilidade dos pisos intertravados de concreto, propondo uma destinação técnica e ecologicamente correta a este resíduo. 


\section{MATERIAIS E MÉTODOS}

\subsection{MATERIAIS}

Para o desenvolvimento desta pesquisa foram utilizados blocos de piso intertravados com: cimento, agregado miúdo, agregado graúdo, pó de brita, água e aditivo plastificante.

O cimento utilizado na fabricação dos blocos foi o CP-II-F-32 com as seguintes características:

- Índice de finura por meio da peneira $75 \mu \mathrm{m}$ (no 200) de 0,1\%;

- Área específica de Blaine $536 \mathrm{~m}^{2} / \mathrm{kg}$;

- Resistência média à compressão de 17,90 $\mathrm{MPa}, 24,60 \mathrm{MPa}$ e 38,00 MPa aos três, sete e 28 dias, respectivamente;

- Inicio de pega aos 250 minutos (4 horas e 10 minutos);

- $\quad$ Fim de pega aos 330 minutos (5 horas e 30 minutos);

- Perda ao fogo de $12,52 \%$.
Todas essas propriedades do cimento atendem às exigências da norma NBR 11578 (ABNT, 1991), com exceção da perda ao fogo que deveria ser $6,5 \%$.

Como agregado miúdo, foi utilizada areia artificial de granito com massa específica de 2,63 $\mathrm{g} / \mathrm{cm}^{3}$, massa unitária de $1,58 \mathrm{~g} / \mathrm{cm}^{3}$, módulo de finura (MF) de 3,45 e diâmetro máximo (Dmax) de $4,75 \mathrm{~mm}$. A curva granulométrica da areia utilizada na pesquisa está apresentada na Figura 1. A areia não está dentro da zona utilizável, segundo a norma NBR 7211 (ABNT, 2009).

O agregado graúdo utilizado foi brita de granito com massa específica de $2,61 \mathrm{~g} / \mathrm{cm}^{3}$, massa unitária de $1,43 \mathrm{~g} / \mathrm{cm}^{3}$, módulo de finura (MF) de 5,61 e diâmetro máximo (Dmax) de 9,5 mm. A curva granulométrica da brita utilizada na pesquisa está apresentada na Figura 2. Segundo a norma NBR 7211 (ABNT, 2009), a brita é classificada como $4.75 / 12.5$, a brita conhecida popularmente como brita 0 .

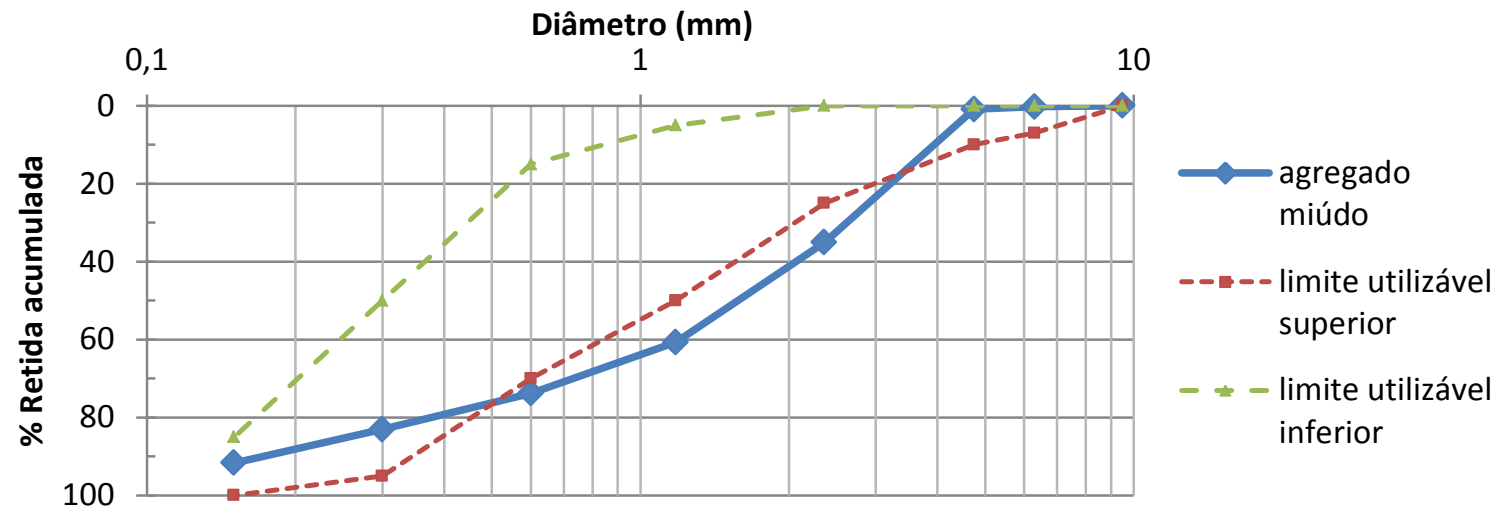

FIGURA 1: Curva de distribuição granulométrica da areia artificial.

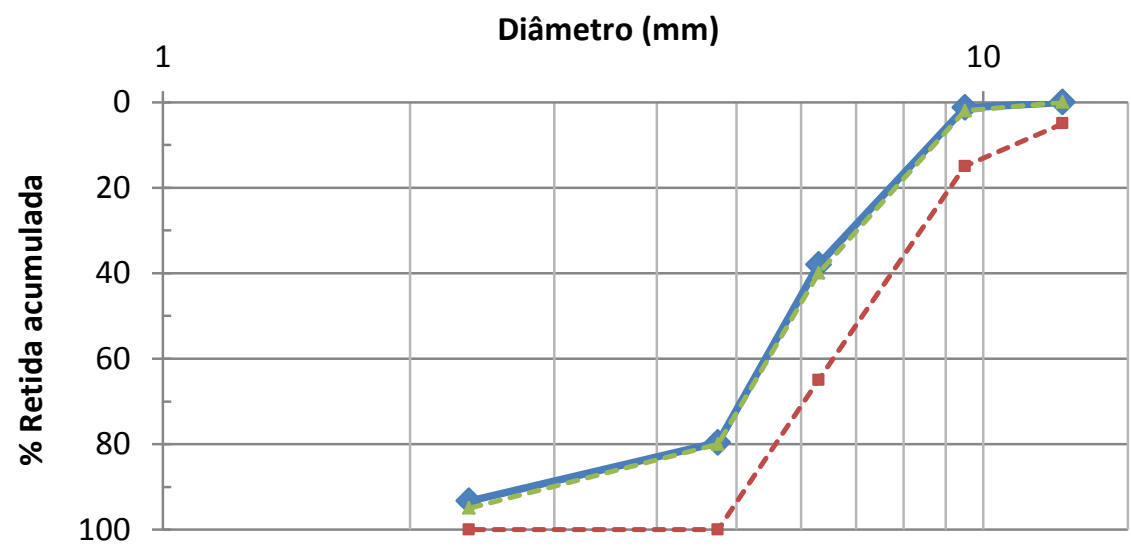

$\sim$ agregado graúdo

--1-- limite superior

$(4.75 / 12.5)$

$--\infty--$ limite inferior

(4.75/12.5)

FIGURA 2: Curva de distribuição granulométrica da brita. 
O fíler utilizado foi o pó de brita. Trata-se de um pó fino e inerte, sem atividade pozolânica. Sua incorporação no concreto contribui para o melhor empacotamento das partículas, além do reaproveitamento de um material geralmente descartado, sem nenhum valor comercial. Ele foi adicionado à mistura para contribuir com o fechamento do pacote granulométrico, preenchendo os vazios deixados pelos grãos de areia e brita. A sua massa específica foi de 2,74 $\mathrm{g} / \mathrm{cm}^{3}$. O tamanho da distribuição das partículas deste material está apresentado na Figura 3.

Para a caracterização mineralógica do pó de brita, foi realizado o ensaio de difração de Raios $X$. Os resultados demonstraram a presença dos minerais como: Stewartita, Quartzo, Ausmanita, Hematita, Butorita, Amesita, Microclíneo e Cianita. Assim, verificou-se que o material em estudo apresenta seus compostos na forma cristalina.

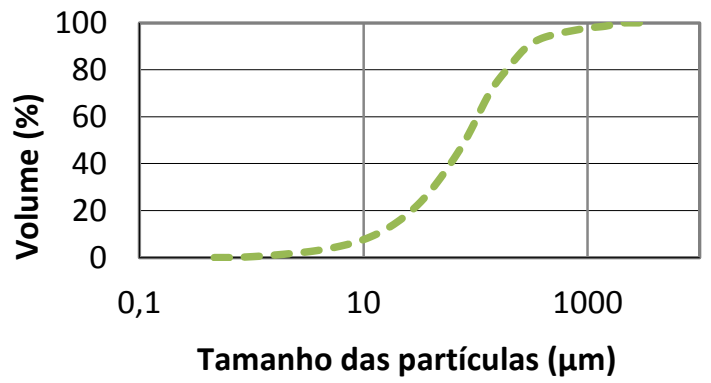

FIGURA 3: Tamanho da distribuição das partículas de pó de brita.

As composições químicas do cimento e do pó de brita estão apresentadas na Tabela 1.

$\mathrm{Na}$ segunda etapa da pesquisa, foi adicionado um aditivo comercial, para avaliar as propriedades do piso, principalmente em relação à absorção de água. $O$ aditivo utilizado foi o Hagen DT Plus da Hagen do Brasil, um aditivo para blocos e pisos, biodegradável, com função plastificante. Segundo a ficha técnica fornecida pelo fabricante, a sua densidade é $1,0 \mathrm{~kg} / \mathrm{L}$ com pH 8,0, base química principal: surfactante à base de alquilsulfonado. As vantagens principais, segundo o fabricante, são facilitar a desforma das peças, aumento da resistência, melhora da aparência e redução do risco de fissuras. Como efeito secundário, aumenta a impermeabilidade.
TABELA 1: Composição química do cimento e do pó de brita (\%).

\begin{tabular}{c|c|c} 
Constituintes & Cimento & Pó Quartzo \\
\hline $\mathrm{CaO}$ & 56,15 & 2,36 \\
$\mathrm{SiO}_{2}$ & 14,83 & 64,36 \\
$\mathrm{SO}_{3}$ & 2,99 & 1,50 \\
$\mathrm{Al}_{2} \mathrm{O}_{3}$ & 3,73 & 22,47 \\
$\mathrm{Fe}_{2} \mathrm{O}_{3}$ & 3,22 & 3,31 \\
$\mathrm{~K}_{2} \mathrm{O}$ & 0,27 & 5,18 \\
$\mathrm{MgO}$ & 5,31 & - \\
$\mathrm{P}_{2} \mathrm{O}_{5}$ & 0,86 & - \\
\hline
\end{tabular}

\subsection{MÉTODOS}

Os pisos utilizados nos ensaios foram produzidos em uma prensa hidráulica com capacidade de $8 \mathrm{tf}$, cedida pela empresa STC Soluções para Construção Civil na cidade de Goiânia. As dimensões dos pisos foram de $12,5 \mathrm{~cm} x$ $25,0 \mathrm{~cm}$, largura e comprimento, respectivamente. A sua altura variou de acordo com os traços e dependeu da capacidade de compactação do equipamento de prensagem, ficando em torno de 8 $\mathrm{cm}$.

Buscando um melhor empacotamento de partículas, utilizou-se uma proporção entre os agregados de $48 \%$ de agregado miúdo e $52 \%$ de graúdo, proporção esta determinada num ensaio para determinação da maior massa unitária da mistura agregado graúdo e agregado miúdo. Para tanto, colocou-se num volume conhecido a brita e determinou-se a sua massa unitária inicial. A seguir, foram feitas substituições parciais de 2 em $2 \%$ da brita pela areia. Após cada substituição o volume era colocado numa mesa vibratória por 2 minutos e determinadas as massas unitárias, até que este valor chegou ao seu valor máximo. Este valor foi determinado quando, ao se substituir parte da brita pela areia, a massa unitária se manteve constante. Foram adotados traços para estudo com as seguintes proporções cimento: agregados totais secos: $1: 2 ; 1: 3 ; 1: 4 ; 1: 5$ e 1:6. Inicialmente, pensouse em trabalhar com outros traços mais fracos (1:7; 1:8 e 1:9), porém a capacidade de prensagem do equipamento não foi suficiente para promover a 
coesão destes traços. Durante a fabricação do traço 1:6 (traço mais fraco estudado), os pisos já estavam se quebrando ao serem retirados da prensa. Assim, foram estudados seis traços no total, sendo um traço referência 1:2 (sem resíduo) e todos os outros traços tiveram uma substituição de $10 \%$ dos agregados totais pelo resíduo. As proporções dos traços estudados nessa pesquisa estão na Tabela 2.

A pesquisa foi dividida em duas etapas, com os traços apresentados anteriormente, porém com diferenças no teor de água. Na primeira etapa, o teor de água adotado foi de $5 \%$ da massa total de materiais secos. Este teor foi adotado por ser ele comumente adotado nas indústrias de artefatos de cimento. Já na segunda etapa, onde se utilizou o aditivo plastificante, substituiu-se parte da água pelo aditivo, ficando um teor de água mais aditivo igual a 5,4\% em relação à massa total de materiais secos. $O$ aditivo plastificante foi utilizado na proporção de 1,5\% em relação à massa de cimento.
Na apresentação e análise dos resultados, os traços da primeira etapa foram identificados com a sigla SA (sem aditivo) e os traços da segunda etapa com a sigla CA (com aditivo).

Para cada traço, foram feitos 24 pisos, sendo 18 para ensaio de resistência à compressão (aos sete, 28 e 90 dias) e seis para ensaio de absorção de água (aos sete e 28 dias).

Visando a homogeneização dos agregados, procederam-se sua secagem e quarteamento. A quantidade necessária para fazer cada traço foi pesada e ensacada, como pode ser observado na Figura 4. No preparo de cada traço, a mistura foi feita em uma betoneira com capacidade de 400 litros (Figura 5), limpa e umidificada. Os materiais foram colocados na seguinte sequência: brita, areia, misturados por três minutos, acréscimo do resíduo e do cimento, misturados por mais três minutos e finalmente, acréscimo de água misturada até a verificação da homogeneização da mistura.

\begin{tabular}{c|c|c|c|c|}
\hline \multicolumn{5}{|c|}{ TABELA 2: Composição dos traços em massa. } \\
\hline Traço & Cimento & $\begin{array}{c}\text { Agregado } \\
\text { Graúdo }\end{array}$ & $\begin{array}{c}\text { Agregado } \\
\text { Miúdo }\end{array}$ & Pó de brita \\
\hline $1: 2$ & 1 & 1,04 & 0,96 & - \\
$1: 2 \mathrm{R}$ & 1 & 0,94 & 0,86 & 0,20 \\
$1: 3 \mathrm{R}$ & 1 & 1,40 & 1,30 & 0,30 \\
$1: 4 \mathrm{R}$ & 1 & 1,87 & 1,73 & 0,40 \\
$1: 5 \mathrm{R}$ & 1 & 2,34 & 2,16 & 0,50 \\
$1: 6 \mathrm{R}$ & 1 & 2,81 & 2,59 & 0,60 \\
\hline
\end{tabular}

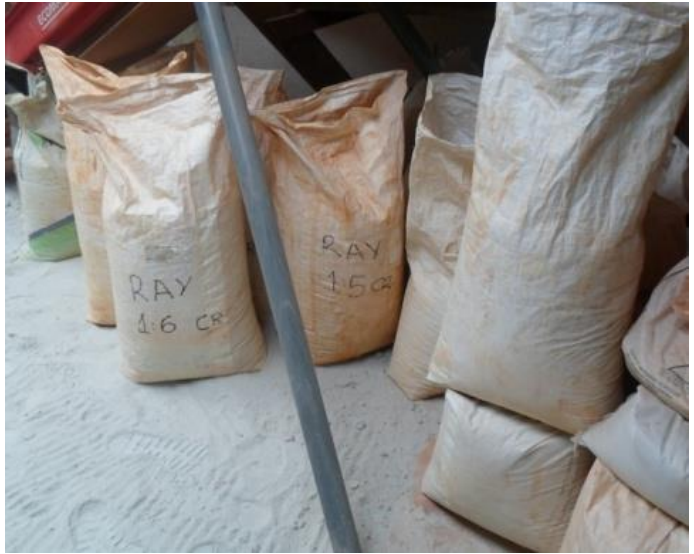

FIGURA 4: Materiais separados e ensacados.

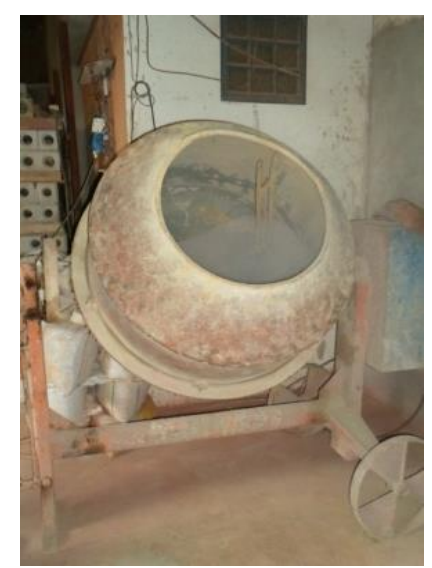

FIGURA 5: Betoneira utilizada. 
O concreto foi transferido para a prensa, onde os pisos foram moldados (Figura 6). Após a prensagem os pisos foram estocados como mostra a Figura 7, protegidos do sol e do vento. O procedimento de cura consistiu em aspergir água uma vez ao dia sobre os pisos, até o dia anterior aos ensaios.

Os ensaios realizados foram: resistência à compressão simples e absorção de água. Estes ensaios foram realizados no laboratório de materiais de construção da Escola de Engenharia Civil da UFG, seguindo-se os procedimentos da NBR 9781 (ABNT,2013) - Peças de concreto para pavimentação - especificação e métodos de ensaio.

No ensaio de resistência à compressão simples, os pisos foram capeados com argamassa dos dois lados do piso com espessura de cerca de
$3 \mathrm{~mm}$, conforme indicado na Figura 8, e posteriormente rompidos na prensa hidráulica do laboratório, como mostra a Figura 9. Quanto ao ensaio de absorção, primeiramente foi feita a secagem dos pisos: três corpos de prova de cada traço foram colocados em estufa com temperatura de $110 \pm 5^{\circ} \mathrm{C}$ por 24 horas (Figura 10). Após a secagem, retiraram-se os corpos de prova da estufa e determinou-se sua massa seca (m1). Em uma segunda parte desse ensaio, os pisos foram saturados de água (Figura 11), para determinação da massa saturada (m2). Após 24 horas imersos, eles foram retirados da água e pesados, como se indica na Figura 12.

A taxa de absorção de água (A) é a razão entre a massa de água absorvida e a massa seca do piso, dada em porcentagem.

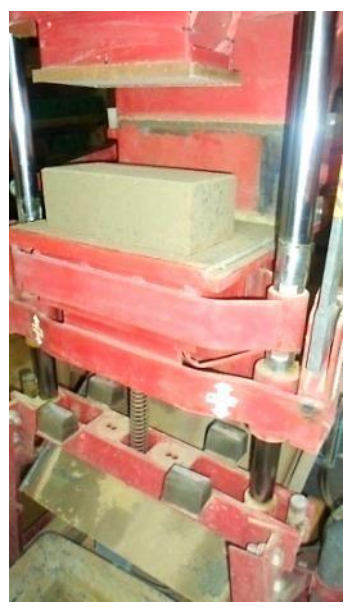

Figura 6: Fabricação do piso.

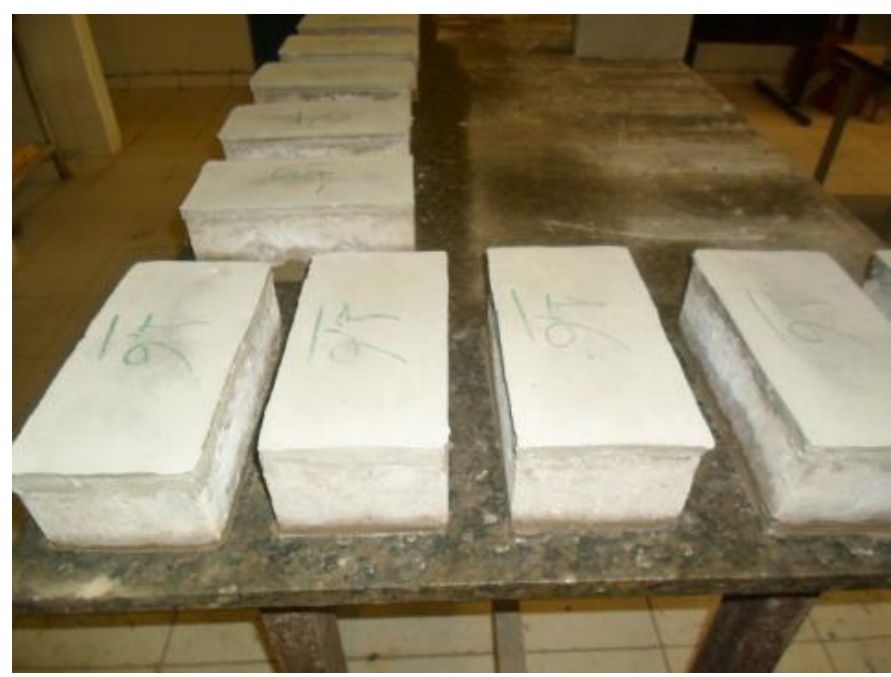

Figura 8: Capeamento dos pisos.

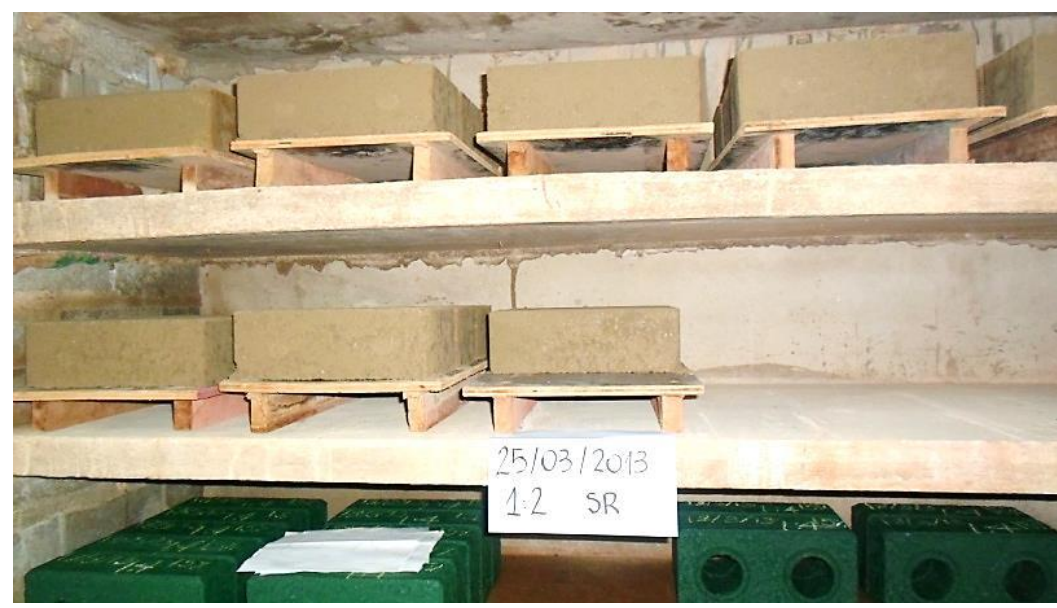

Figura 7: Local de cura dos pisos

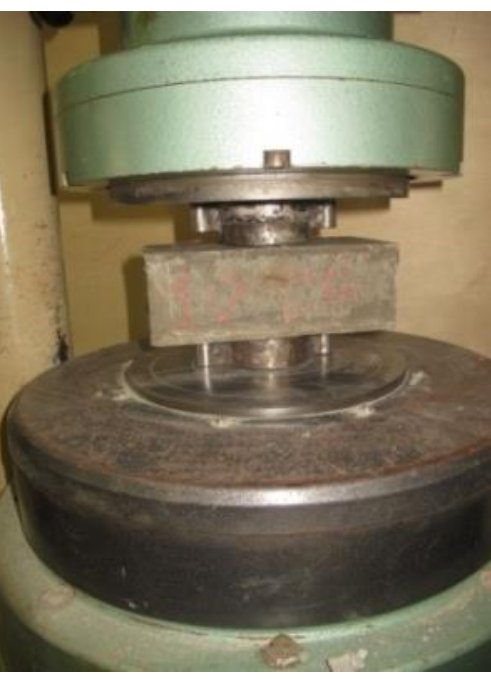

Figura 9: Ensaio com placas auxiliadoras de $90 \mathrm{~mm}$. 


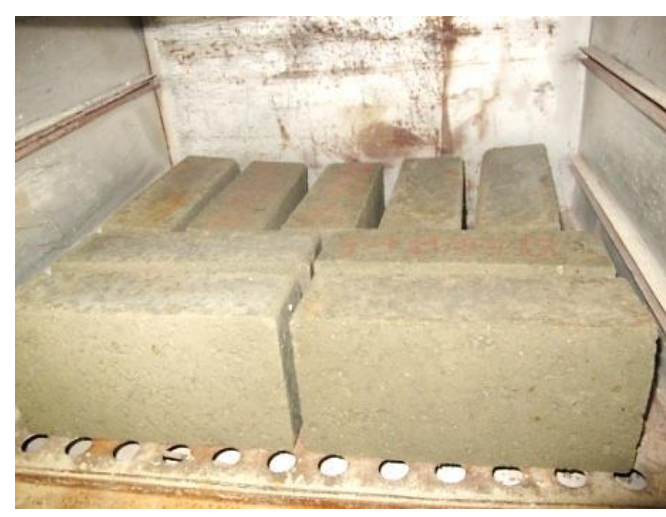

Figura 10: Pisos na estufa.

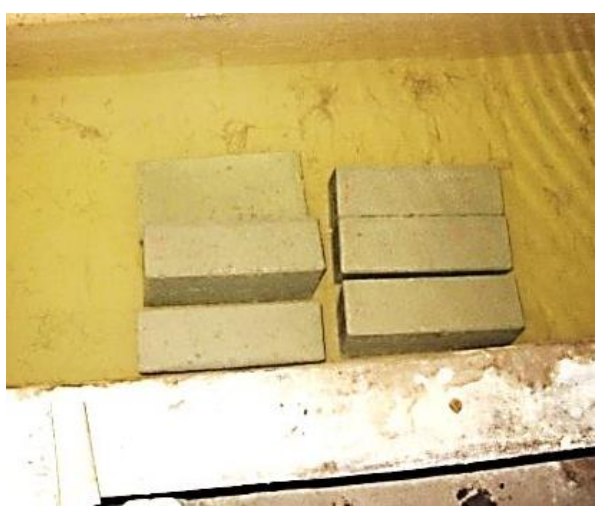

Figura 11: Saturação dos pisos.

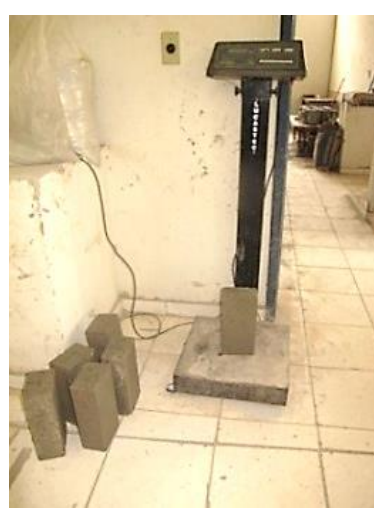

Figura 12: Pesagem dos pisos saturados.

\section{RESULTADOS E DISCUSSÕES}

\subsection{PRIMEIRA ETAPA}

São apresentados os resultados do desempenho dos pisos fabricados sem uso do aditivo (SA) plastificante, nos ensaios de resistência à compressão simples e absorção de água.

\subsubsection{Ensaio de Resistência à Compressão Simples}

Os resultados estão apresentados nas Tabelas 3, 4 e 5 com os valores individuais, médias e desvios padrões. Estes resultados estão sintetizados nos gráficos das Figuras 13, 14 e 15, para cada idade de ruptura.

\section{TABELA 3: Resultados ensaio de resistência à compressão (MPa) - 7 dias.}

\begin{tabular}{c|c|c|c|c|c|c}
\multirow{2}{*}{$\begin{array}{c}\text { Corpo de } \\
\text { prova }\end{array}$} & \multicolumn{6}{|c}{ Traço } \\
\cline { 2 - 7 } & $\mathbf{1 : 2 ~ S A}$ & $\mathbf{1 : 2 ~ R ~ S A ~}$ & $\mathbf{1 : 3 ~ R ~ S A ~}$ & $\mathbf{1 : 4 ~ R ~ S A ~}$ & $\mathbf{1 : 5 ~ R ~ S A ~}$ & $\mathbf{1 : 6 ~ R ~ S A ~}$ \\
\hline $\mathbf{1}$ & 10,14 & 10,45 & 10,22 & 8,88 & 7,56 & 7,47 \\
$\mathbf{2}$ & 10,61 & 13,83 & 11,95 & 9,59 & 9,04 & 7,23 \\
$\mathbf{3}$ & 9,82 & 11,00 & 10,37 & 8,17 & 8,88 & 7,07 \\
$\mathbf{4}$ & 10,14 & 12,03 & 10,14 & - & 7,55 & 5,42 \\
$\mathbf{5}$ & 10,30 & 13,75 & 10,92 & - & 8,80 & 6,60 \\
$\mathbf{6}$ & 10,85 & 13,52 & 10,37 & - & 7,86 & 7,07 \\
\hline Média (MPa) & 10,31 & 12,43 & 10,66 & 8,88 & 8,33 & 6,81 \\
\hline Desvio (MPa) & 0,37 & 1,48 & 0,69 & 0,71 & 0,65 & 0,74 \\
\hline
\end{tabular}

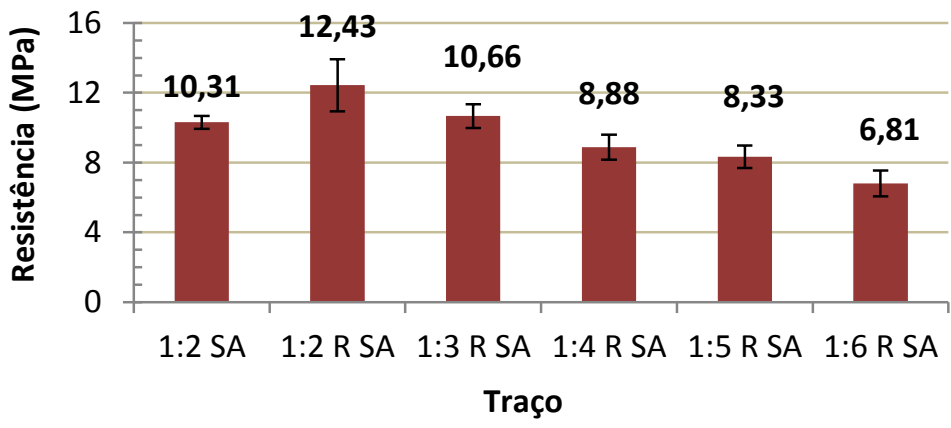

FIGURA 13: Resistência à compressão - 7dias. 
TABELA 4: Resultados ensaio de resistência à compressão (MPa) - 28 dias.

\begin{tabular}{c|c|c|c|c|c|c}
\multirow{2}{*}{$\begin{array}{c}\text { Corpo de } \\
\text { prova }\end{array}$} & \multicolumn{7}{|c}{ Traço } \\
\cline { 2 - 7 } & $\mathbf{1 : 2 ~ S A}$ & $\mathbf{1 : 2 ~ R ~ S A}$ & $\mathbf{1 : 3 ~ R ~ S A ~}$ & $\mathbf{1 : 4 ~ R ~ S A ~}$ & $\mathbf{1 : 5 ~ R ~ S A ~}$ & $\mathbf{1 : 6 ~ R ~ S A ~}$ \\
\hline $\mathbf{1}$ & 15,56 & 15,40 & 14,85 & 12,34 & 10,69 & 8,96 \\
$\mathbf{2}$ & 15,88 & 19,02 & 14,62 & 12,10 & 10,53 & 9,90 \\
$\mathbf{3}$ & 15,72 & 15,88 & 15,56 & 12,58 & 9,59 & 8,65 \\
$\mathbf{4}$ & 16,33 & 19,49 & 15,56 & 12,26 & 9,90 & 8,33 \\
$\mathbf{5}$ & 15,22 & 17,92 & 15,64 & 12,42 & 10,06 & 6,44 \\
$\mathbf{6}$ & 13,60 & 18,47 & 14,85 & 112,58 & 9,75 & 7,86 \\
\hline Média (MPa) & 15,38 & 17,70 & 15,18 & 12,38 & 10,09 & 8,36 \\
\hline Desvio (MPa) & 0,95 & 1,68 & 0,45 & 0,18 & 0,44 & 1,16 \\
\hline
\end{tabular}

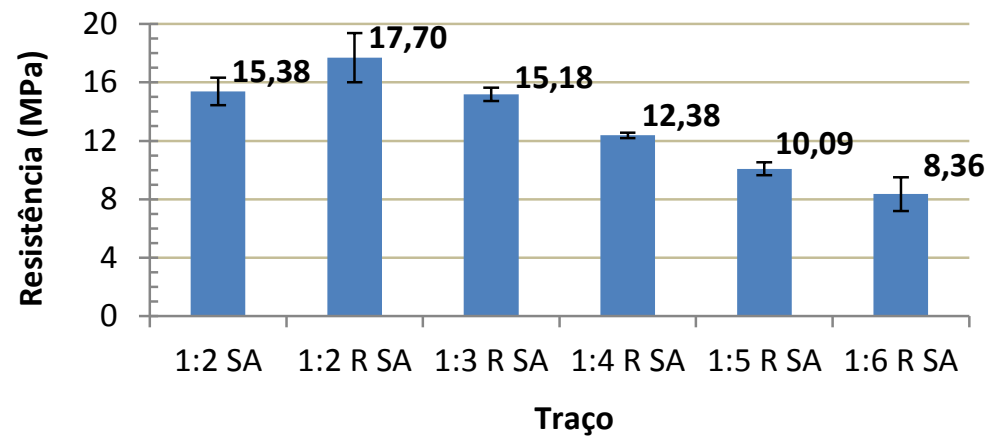

FIGURA 14: Resistência à compressão - 28 dias.

TABELA 5: Resultados ensaio de resistência à compressão (MPa) - 90 dias.

\begin{tabular}{c|c|c|c|c|c|c}
\multirow{2}{*}{$\begin{array}{c}\text { Corpo de } \\
\text { prova }\end{array}$} & \multicolumn{6}{|c}{ Traço } \\
\cline { 2 - 7 } & $\mathbf{1 : 2 ~ S A}$ & $\mathbf{1 : 2 ~ R ~ S A ~}$ & $\mathbf{1 : 3 ~ R ~ S A ~}$ & $\mathbf{1 : 4 ~ R ~ S A ~}$ & $\mathbf{1 : 5 ~ R ~ S A ~}$ & $\mathbf{1 : 6 ~ R ~ S A ~}$ \\
\hline $\mathbf{1}$ & 20,12 & 24,99 & 19,81 & 14,70 & 13,05 & 9,43 \\
$\mathbf{2}$ & 19,02 & 19,18 & 17,29 & 15,40 & 13,99 & 10,53 \\
$\mathbf{3}$ & 19,33 & 17,45 & 19,33 & 15,48 & 13,36 & 9,43 \\
$\mathbf{4}$ & 18,23 & 22,64 & 19,18 & 14,93 & 9,43 & 10,53 \\
$\mathbf{5}$ & 21,38 & 23,26 & 19,65 & 16,66 & 11,79 & 9,90 \\
$\mathbf{6}$ & 18,71 & 18,23 & 20,28 & 15,72 & 10,53 & 10,37 \\
\hline Média (MPa) & 19,47 & 20,96 & 19,26 & 15,48 & 12,03 & 10,03 \\
\hline Desvio (MPa) & 1,13 & 3,08 & 1,04 & 0,69 & 1,77 & 0,52 \\
\hline
\end{tabular}




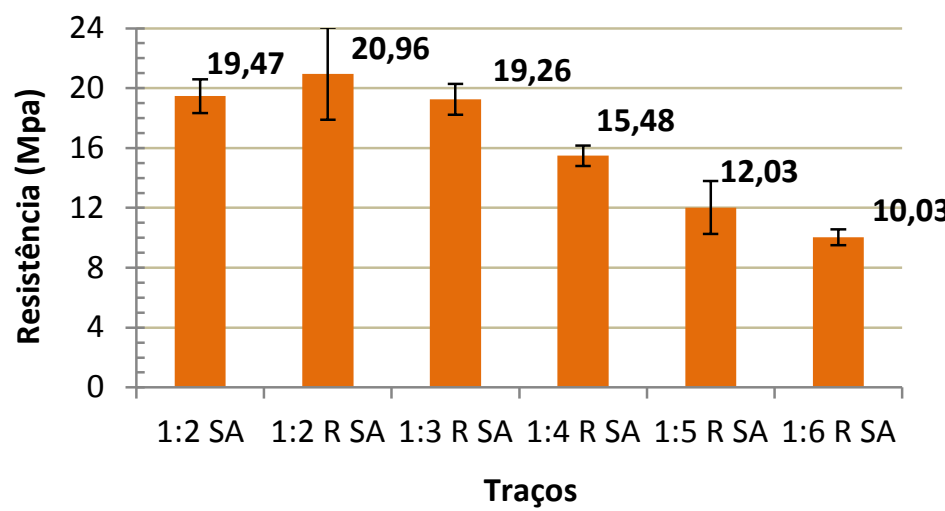

FIGURA 15: Resistência à compressão - 90dias.

O gráfico da Figura 16 apresenta o resumo dos resultados obtidos para a primeira etapa, com as resistências para todos os traços em todas as idades.

Analisando-se os resultados de resistência à compressão dos traços 1:2 e 1:2 R em todas as idades, observa-se que a incorporação do pó de brita promoveu ganhos de resistências: 20,6\% , $15,1 \%$ e $7,7 \%$ aos sete, 28 e 90 dias, respectivamente.

Observa-se, do gráfico da Figura 16, que o traço 1:3RSA produziu resultados semelhantes aos do traço 1:2 SA, mais rico em cimento. Tal fato pode ser atribuído à falta de hidratação de todo o cimento deste traço mais rico e ao melhor empacotamento das partículas do traço 1:3RSA.
Quando se analisa do traço 1:2RSA para o traço 1:6RSA, observa-se nítida redução das resistências à compressão nas três idades. Isto era esperado em função da contínua redução do cimento até se chegar ao traço 1:6RSA.

Pela NBR 9781 (ABNT, 2013), a resistência característica à compressão aos 28 dias de peças de concreto para pavimentação para tráfego de pedestre, veículos leves e comerciais de linha deve ser no mínimo $35 \mathrm{MPa}$. Os resultados obtidos ficaram abaixo dos exigidos por essa norma, porém o objetivo desta pesquisa foi analisar o efeito da incorporação do pó de brita nos pisos intertravados. Além disso, no quesito resistência, os pisos pesquisados poderiam ser usados em calçadas, para tráfego de pessoas.

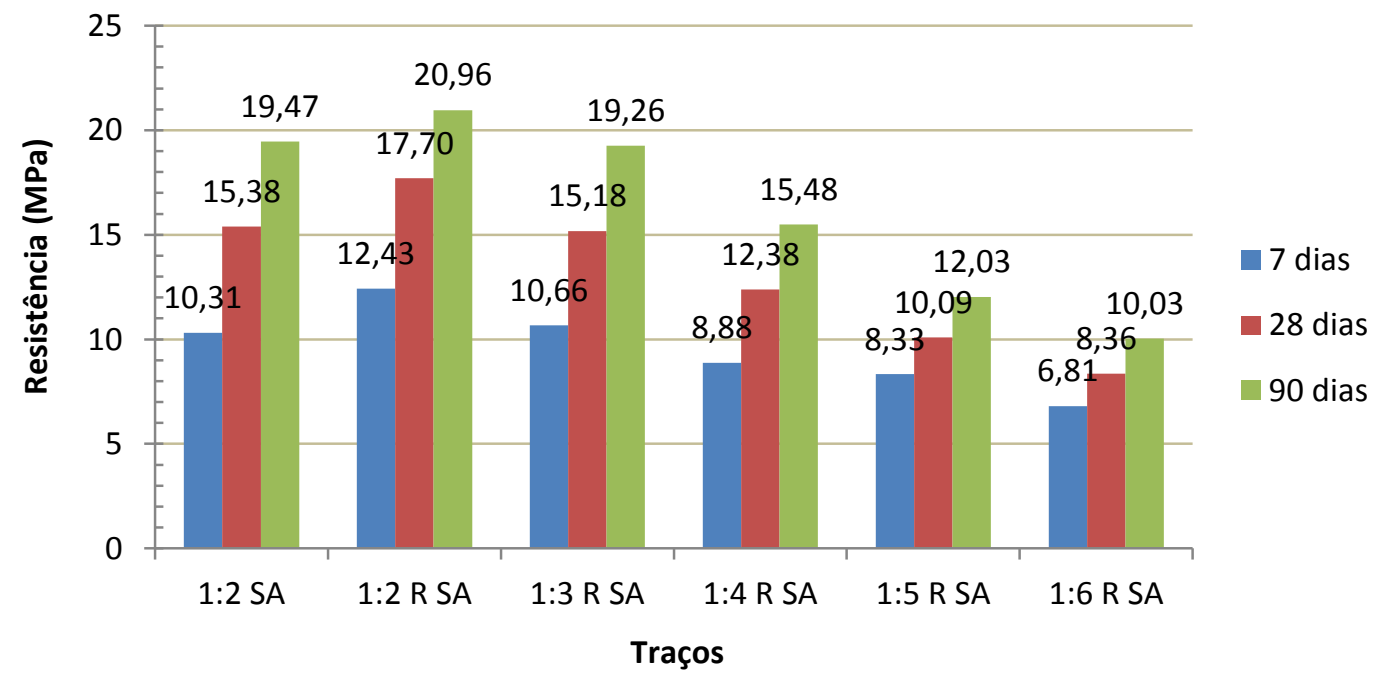

FIGURA 16: Resistência à compressão - resumo primeira etapa. 


\subsubsection{Ensaio de Absorção de água}

Para a primeira etapa dessa pesquisa, o ensaio de absorção de água pelos corpos de prova só foi realizado aos 28 dias. Seguem os resultados na Tabela 6 e no gráfico da Figura 17.

Analisando-se as médias e os respectivos desvios, observam-se dois comportamentos distintos quanto à absorção. Estatisticamente, os traços 1:2SA, 1:2RSA e 1:3RSA formam um primeiro grupo, com uma absorção média de $11,84 \%$; Já os traços 1:4RSA, 1:5RSA e 1:6RSA formam um segundo grupo, com uma absorção média de 10,37\%, aproximadamente $12 \%$ inferior.

Todos os resultados de absorção sem o uso do aditivo ficaram acima do especificado pela NBR 9781 (ABNT, 2013). Segundo essa norma, o valor médio da absorção de água deve ser menor ou igual a $6 \%$, não sendo admitido nenhum valor individual maior do que $7 \%$.

\subsection{SEGUNDA ETAPA}

São apresentados os resultados do desempenho dos pisos fabricados com uso do aditivo plastificante para concreto seco (Hagen DT Plus), para os ensaios de resistência à compressão simples e absorção de água.

\subsubsection{Ensaio de Resistência à Compressão Simples}

As Tabelas 7, 8 e 9 e os gráficos das Figuras 18,19 e 20 mostram os resultados dos ensaios de resistência à compressão simples realizados nos corpos de prova considerando 7, 28 e 90 dias, respectivamente.

\begin{tabular}{c|c|c|c|c|c|c}
\hline \multirow{5}{*}{$\begin{array}{c}\text { Corpo de } \\
\text { prova }\end{array}$} & \multicolumn{7}{|c}{ TABELA 6: Resultados ensaio de absorção de água (\%). } \\
\cline { 2 - 7 } & $\mathbf{1 : 2 ~ S A}$ & $\mathbf{1 : 2}$ R SA & $\mathbf{1 : 3 ~ R ~ S A ~}$ & $\mathbf{1 : 4 ~ R ~ S A ~}$ & $\mathbf{1 : 5}$ R SA & $\mathbf{1 : 6 ~ R ~ S A ~}$ \\
\hline $\mathbf{1}$ & 11,89 & 11,11 & 11,51 & 10,29 & 10,12 & 10,20 \\
$\mathbf{2}$ & 11,79 & 13,81 & 11,24 & 10,48 & 9,96 & 10,79 \\
$\mathbf{3}$ & 11,93 & 11,76 & 11,51 & 10,98 & 10,57 & 9,96 \\
\hline Média (\%) & 11,87 & 12,23 & 11,42 & 10,58 & 10,22 & 10,32 \\
\hline Desvio (\%) & 0,07 & 1,41 & 0,15 & 0,35 & 0,32 & 0,43 \\
\hline
\end{tabular}

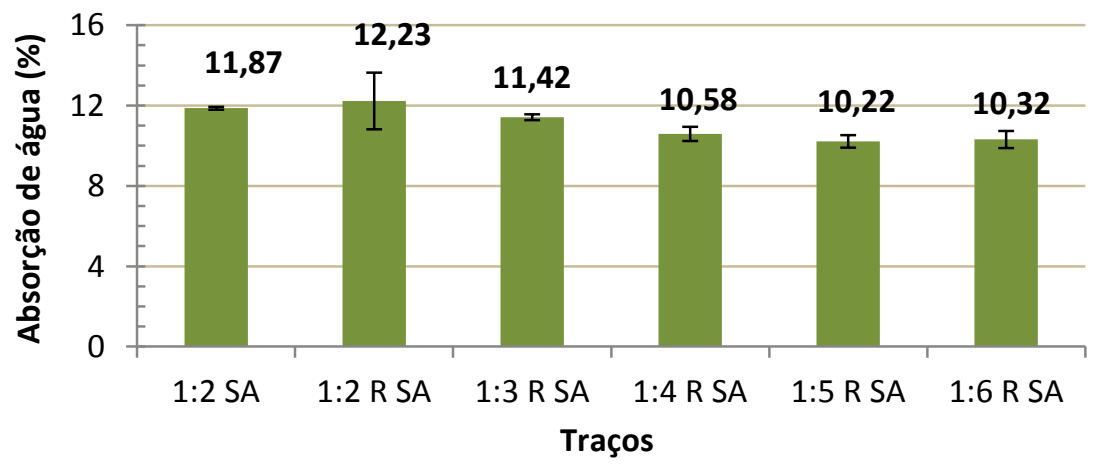

FIGURA 17: Absorção de água - primeira etapa. 


\section{TABELA 7: Resultados ensaio de resistência à compressão (MPa) - 7 dias.}

\begin{tabular}{c|c|c|c|c|c|c}
\hline \multirow{2}{*}{$\begin{array}{c}\text { Corpo de } \\
\text { prova }\end{array}$} & \multicolumn{6}{|c}{ Traço } \\
\cline { 2 - 7 } & $\mathbf{1 : 2} \mathbf{~ C A}$ & $\mathbf{1 : 2}$ R CA & $\mathbf{1 : 3 ~ R ~ C A ~}$ & $\mathbf{1 : 4 ~ R ~ C A ~}$ & $\mathbf{1 : 5 ~ R ~ C A ~}$ & $\mathbf{1 : 6 ~ R ~ C A ~}$ \\
\hline $\mathbf{1}$ & 8,02 & 8,65 & 10,06 & 6,29 & 5,97 & 5,50 \\
$\mathbf{2}$ & 9,12 & 8,65 & 10,06 & 6,44 & 5,50 & 4,72 \\
$\mathbf{3}$ & 8,80 & 10,69 & 9,27 & 6,76 & 5,34 & 4,40 \\
$\mathbf{4}$ & 8,02 & 8,49 & 8,96 & 6,13 & 5,50 & 5,34 \\
$\mathbf{5}$ & 8,80 & 9,75 & 10,22 & 5,82 & 5,82 & 6,29 \\
$\mathbf{6}$ & 9,12 & 10,53 & 8,02 & 6,92 & 5,66 & 4,56 \\
\hline Média (MPa) & 8,65 & 9,46 & 9,43 & 6,39 & 5,63 & 5,13 \\
\hline Desvio (MPa) & 0,51 & 1,00 & 0,86 & 0,41 & 0,23 & 0,71 \\
\hline
\end{tabular}

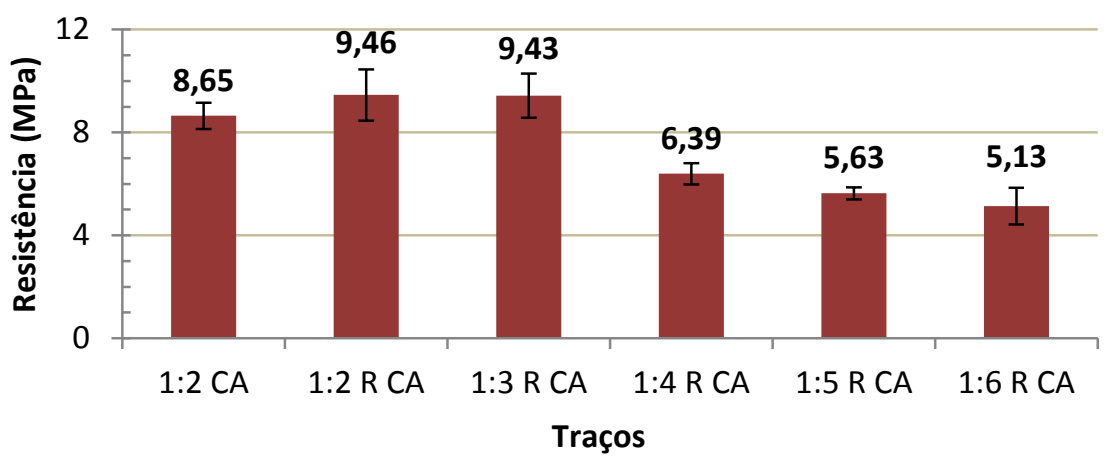

FIGURA 18: Resistência à compressão - 7 dias.

TABELA 8: Resultados ensaio de resistência à compressão (MPa) - 28 dias.

\begin{tabular}{|c|c|c|c|c|c|c|}
\hline \multirow{2}{*}{$\begin{array}{c}\text { Corpo de } \\
\text { prova }\end{array}$} & \multicolumn{6}{|c|}{ Traço } \\
\hline & $1: 2 \mathrm{CA}$ & 1:2 R CA & 1:3 R CA & 1:4 R CA & 1:5 R CA & 1:6 R CA \\
\hline 1 & 8,17 & 9,75 & 10,37 & 8,96 & 9,75 & 9,59 \\
\hline 2 & 7,86 & 9,43 & 8,65 & 6,60 & 7,86 & 8,65 \\
\hline 3 & 7,07 & 9,59 & 10,53 & 5,66 & 9,12 & 7,70 \\
\hline 4 & 7,70 & 9,27 & 10,06 & 7,70 & 6,60 & 8,96 \\
\hline 5 & 7,39 & 8,80 & 10,69 & 8,17 & 9,90 & 10,06 \\
\hline 6 & 6,92 & 8,49 & 10,53 & 9,59 & 9,43 & 9,43 \\
\hline Média (MPa) & 7,52 & 9,22 & 10,14 & 7,78 & 8,78 & 9,06 \\
\hline Desvio (MPa) & 0,48 & 0,48 & 0,76 & 1,46 & 1,29 & 0,83 \\
\hline
\end{tabular}




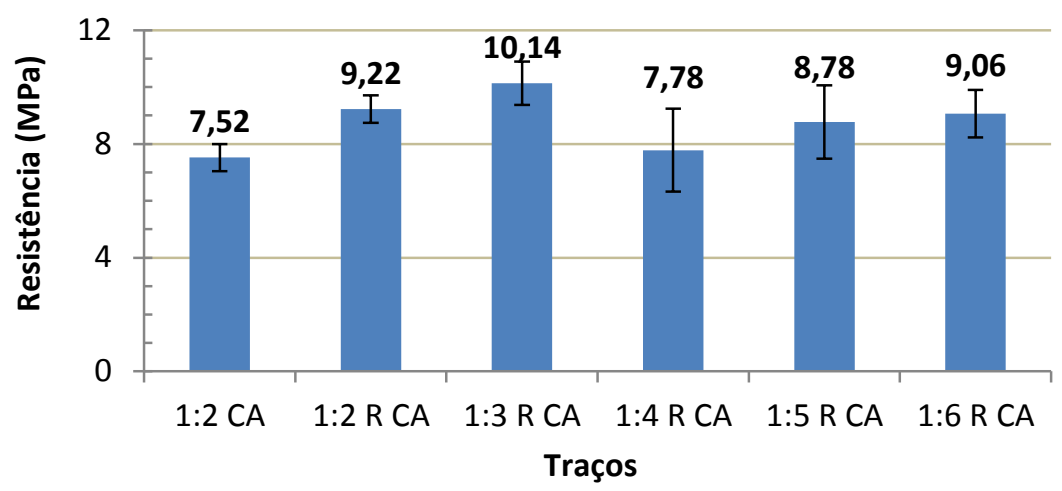

FIGURA 19: Resistência à compressão - 28 dias.

TABELA 9: Resultados ensaio de resistência à compressão (MPa) - 90 dias.

\begin{tabular}{c|c|c|c|c|c|c}
\multirow{2}{*}{$\begin{array}{c}\text { Corpo de } \\
\text { prova }\end{array}$} & \multicolumn{6}{|c}{ Traço } \\
\cline { 2 - 7 } & $\mathbf{1 : 2 ~ C A}$ & $\mathbf{1 : 2 ~ R ~ C A ~}$ & $\mathbf{1 : 3 ~ R ~ C A ~}$ & $\mathbf{1 : 4 ~ R ~ C A ~}$ & $\mathbf{1 : 5 ~ R ~ C A ~}$ & $\mathbf{1 : 6 ~ R ~ C A ~}$ \\
\hline $\mathbf{1}$ & 8,81 & 7,05 & 8,28 & 11,10 & 8,11 & 6,70 \\
$\mathbf{2}$ & 10,04 & 8,46 & 10,57 & 12,34 & 6,60 & 6,76 \\
$\mathbf{3}$ & 8,99 & 9,69 & 8,99 & 10,93 & 7,70 & 6,44 \\
$\mathbf{4}$ & 8,28 & 6,17 & 8,46 & 10,22 & 8,17 & 7,86 \\
$\mathbf{5}$ & 8,64 & 10,04 & 8,11 & 10,04 & 8,33 & 7,70 \\
$\mathbf{6}$ & 8,11 & 9,34 & 9,16 & 8,11 & 10,22 & 8,80 \\
\hline Média (MPa) & 8,81 & 8,46 & 8,93 & 10,46 & 8,19 & 7,38 \\
\hline Desvio (MPa) & 0,69 & 1,55 & 0,90 & 1,41 & 1,17 & 0,90 \\
\hline
\end{tabular}

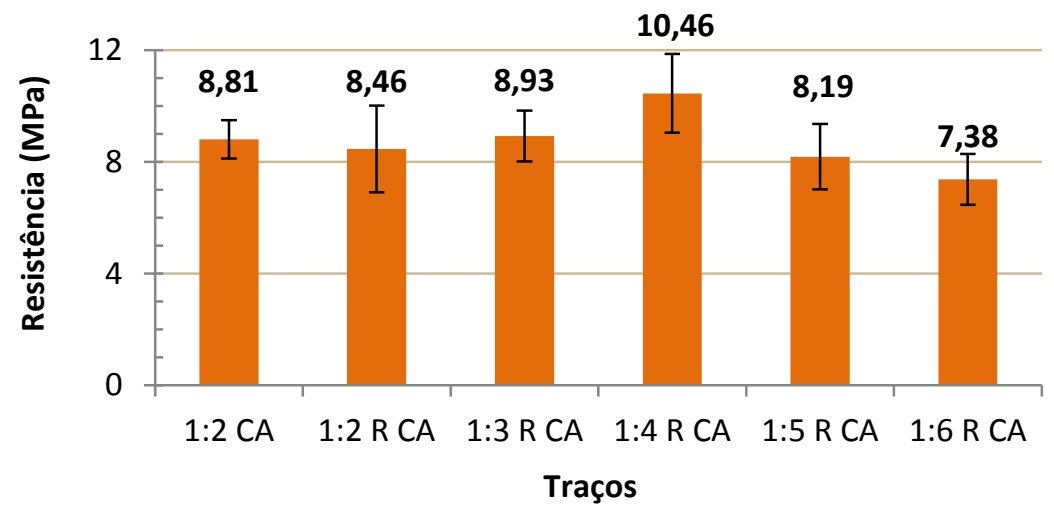

FIGURA 20: Resistência à compressão - 90 dias. 
O gráfico da Figura 21 é um resumo dos resultados obtidos na segunda etapa, com as resistências para todos os traços em todas as idades.

Comparando-se o gráfico da Figura 21 com o gráfico da Figura 16, verifica-se que a incorporação do aditivo provocou uma redução nos valores das resistências para todos os traços e em todas as idades, com exceção do traço 1:6 aos 28 dias que, pelo desvio padrão, apresenta valores iguais. Com o aditivo plastificante também se verificou que o traço 1:3RSA produziu resultados semelhantes aos do traço 1:2 SA, mais rico em cimento.

\subsubsection{Ensaio de Absorção de água}

As Tabelas 10 e 11 e os gráficos das Figuras 22 e 23 apresentam os resultados dos ensaios de absorção de água dos corpos de prova aos 07 e 28 dias, respectivamente.

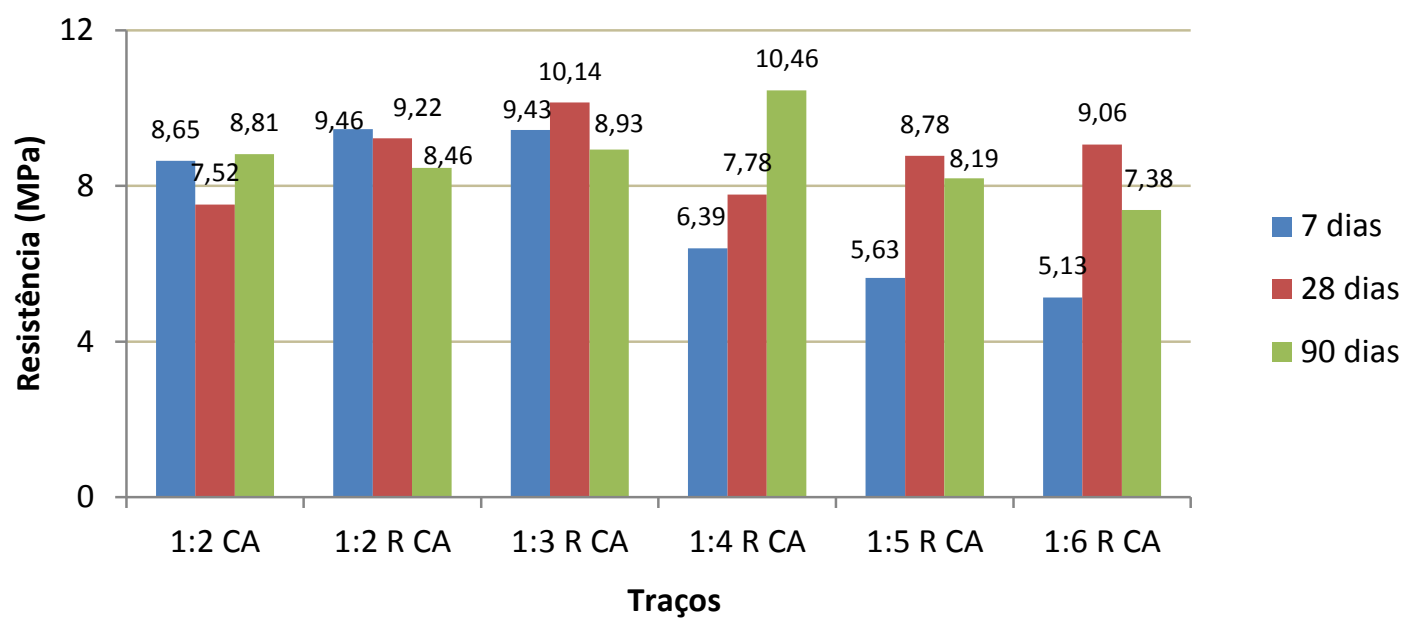

FIGURA 21: Resistência à compressão - Resumo segunda etapa.

\begin{tabular}{c|c|c|c|c|c|c}
\hline \multicolumn{7}{|c}{ TABELA 10: Resultados ensaio de absorção de água (\%) - 7 dias. } \\
\hline \multirow{2}{*}{$\begin{array}{c}\text { Corpo de } \\
\text { prova }\end{array}$} & \multicolumn{5}{c}{ Traço } \\
\cline { 2 - 7 } & $\mathbf{1 : 2 ~ C A}$ & $\mathbf{1 : 2}$ R CA & $\mathbf{1 : 3 ~ R ~ C A ~}$ & $\mathbf{1 : 4 ~ R ~ C A ~}$ & $\mathbf{1 : 5}$ R CA & $\mathbf{1 : 6 ~ R ~ C A ~}$ \\
\hline $\mathbf{1}$ & 2,75 & 2,48 & 3,25 & 6,64 & 8,27 & 9,09 \\
$\mathbf{2}$ & 2,72 & 2,45 & 2,80 & 6,64 & 8,17 & 7,94 \\
$\mathbf{3}$ & 1,95 & 2,89 & 2,41 & 8,27 & 8,27 & 8,06 \\
\hline Média (\%) & 2,47 & 2,61 & 2,82 & 7,18 & 8,24 & 8,36 \\
\hline Desvio (\%) & 0,46 & 0,25 & 0,42 & 0,94 & 0,06 & 0,63 \\
\hline
\end{tabular}




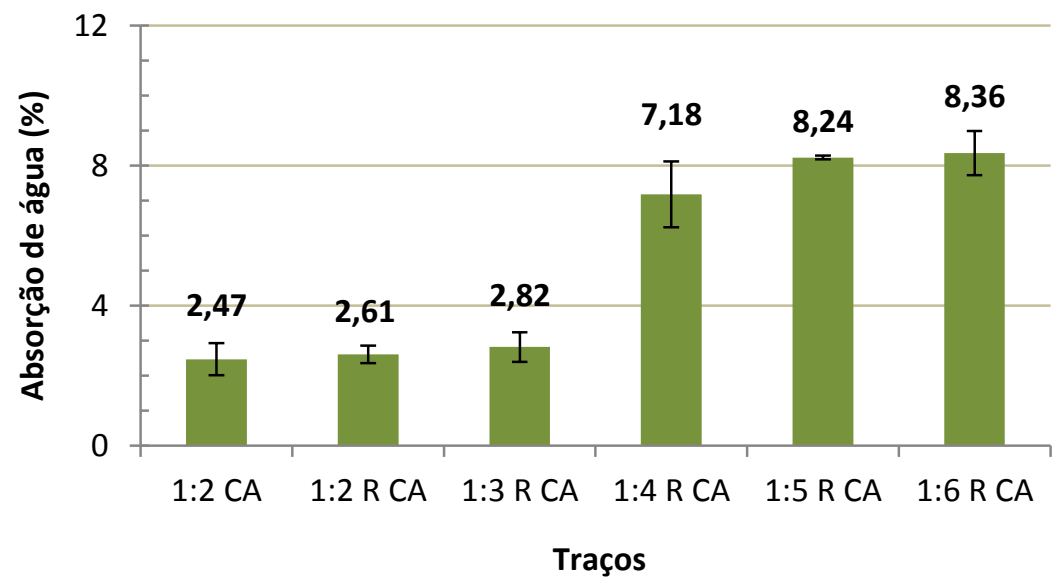

FIGURA 22: Absorção de água - segunda etapa - 7 dias.

\begin{tabular}{c|c|c|c|c|c|c}
\hline \multirow{2}{*}{$\begin{array}{c}\text { Corpo de } \\
\text { prova }\end{array}$} & $\mathbf{1 : 2 ~ C A}$ & $\mathbf{1 : 2}$ R CA & $\mathbf{1 : 3 ~ R ~ C A ~}$ & $\mathbf{1 : 4}$ R CA & $\mathbf{1 : 5 ~ R ~ C A ~}$ & $\mathbf{1 : 6 ~ R ~ C A ~}$ \\
\cline { 2 - 7 } & 3,08 & 3,70 & 3,15 & 6,64 & 6,30 & 7,87 \\
$\mathbf{1}$ & 4,23 & 2,38 & 3,19 & 5,49 & 7,72 & 9,13 \\
$\mathbf{2}$ & 3,42 & 2,88 & 2,04 & 5,53 & 6,61 & 8,80 \\
\hline $\mathbf{3}$ & 3,58 & 2,99 & 2,79 & 5,89 & 6,88 & 8,60 \\
\hline Média (\%) & 0,59 & 0,67 & 0,65 & 0,65 & 0,75 & 0,65 \\
\hline Desvio (\%) &
\end{tabular}

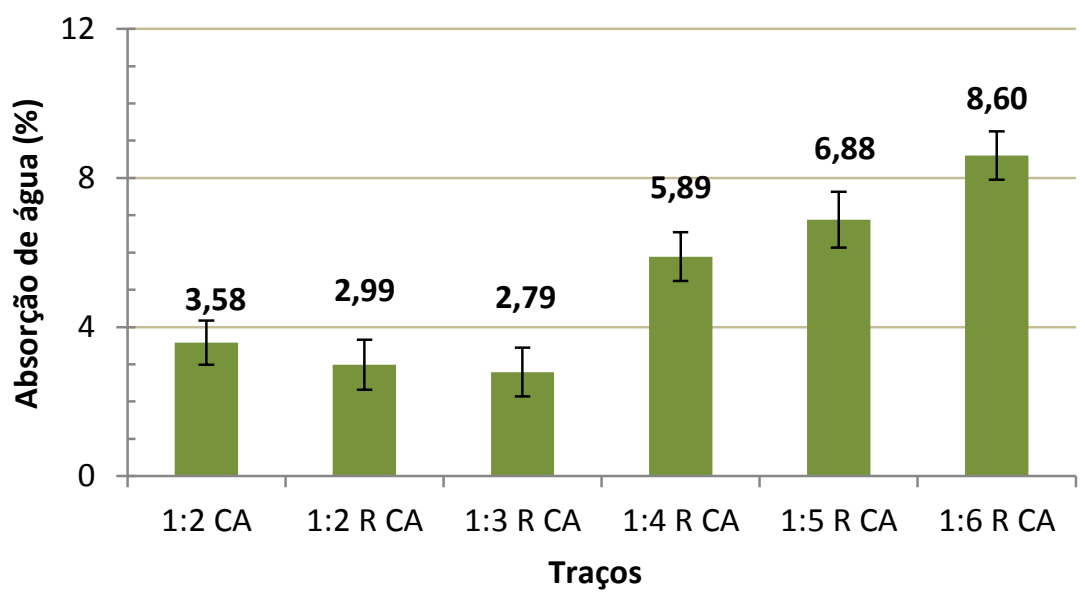

FIGURA 23: Absorção de água - segunda etapa - 28 dias.

Comparando-se os gráficos das Figuras 22 e 23 com o gráfico da Figura 17, constata-se que a incorporação do aditivo plastificante reduziu as absorções. Constata-se ainda, que as reduções foram significativamente maiores para os traços mais ricos em cimento (1:2SA, 1:2RSA e 1:3RSA). Para estes traços os valores ficaram abaixo do limite da norma NBR 9781 (ABNT, 2013).

\section{CONCLUSÕES}

O presente trabalho avaliou o efeito da incorporação de um resíduo mineral proveniente da britagem de rochas, comumente denominado de pó de brita, nas propriedades mecânicas e de durabilidade de pisos intertravados. Avaliou também, o efeito da adição de um aditivo plastificante nestas mesmas propriedades. 
A incorporação do pó de brita promoveu uma tendência de ganho de resistência de cerca de $11 \%$, sem uma variação significativa da absorção de água, confirmando sua viabilidade técnica e ecológica.

Quanto ao aditivo, apesar de promover uma redução significativa nos valores de absorção, promoveu também uma queda na resistência à compressão. Como neste estudo utilizou-se um teor de plastificante de $1,5 \%$ em relação à massa do cimento, novos estudos devem ser realizados com teores diferenciados para traços mais ricos e mais pobres em cimento.

\section{AGRADECIMENTOS}

Os autores agradecem à STC Soluções para Construção Civil, pela doação dos materiais e equipamentos utilizados na confecção dos pisos.

\section{REFERÊNCIAS BIBLIOGRÁFICAS}

ABI-ACKEL, E. Uso dos Resíduos da Construção Civil para a Produção de Pavimento Intertravado a Base de Concreto de Cimento Portland e Escória. 2009. Dissertação (Mestrado em Construção Civil) - Escola de Engenharia, Universidade Federal de Minas Gerais. Belo Horizonte, 2009.

ASSOCIAÇÃO BRASILEIRA DE NORMAS TÉCNICAS. NBR 11578: Cimento Portland composto - Especificação. Rio de Janeiro, 1991.

NBR 7211: Agregados para concreto Especificação. Rio de Janeiro, 2009.

NBR 9781: Peças de concreto para pavimentação - especificação e métodos de ensaio. Rio de Janeiro, 2013. . NBR 9780: Peças de concreto para
pavimentação - Determinação da resistência a
compressão. Rio de Janeiro, 1987.

NBR 9781: Peças de concreto para pavimentação especificação. Rio de Janeiro, 1987.

. NBR NM 52: Agregado miúdo - Determinação da massa específica e massa específica aparente. Rio de Janeiro, 2009.
NBR NM 53: Agregado graúdo - Determinação da massa específica, massa específica aparente e absorção de água. Rio de Janeiro, 2009.

NBR NM 45: Agregados - Determinação da massa unitária e do volume de vazios. Rio de Janeiro, 2006.

NBR NM 248: Agregados - Determinação da composição granulométrica. Rio de Janeiro, 2003.

GENCEL, O.; OZEL, C. et al. Properties of concrete paving blocks made with waste marble. Journal of Cleaner Production, 2011.

HALLACK, Abdo. Pavimento Intertravado: uma solução universal. Revista Prisma, Dezembro 2001, pp 25-27.

INSTITUTO BRASILEIRO DE CONCRETO - IBRACON. Concreto: Ensino, Pesquisa e Realizações. São Paulo, 2005.

PURIFICAÇÃO, E. Estudo do uso de agregados reciclados de concreto e substituição do cimento por resíduo de polimento de porcelanato na produção de pisos intertravados de concreto. 2009. Dissertação (Mestrado em Construção Civil) - Escola de Engenharia, Universidade Federal de Minas Gerais. Belo Horizonte, 2009.

TAVARES, C.; FRANCO, J. Production of concrete paving blocks (CPB) utilising electroplating residues Evaluation of mechanical and micro-structural properties. The Canadian Journal of Chemical Engineering, 2012. 